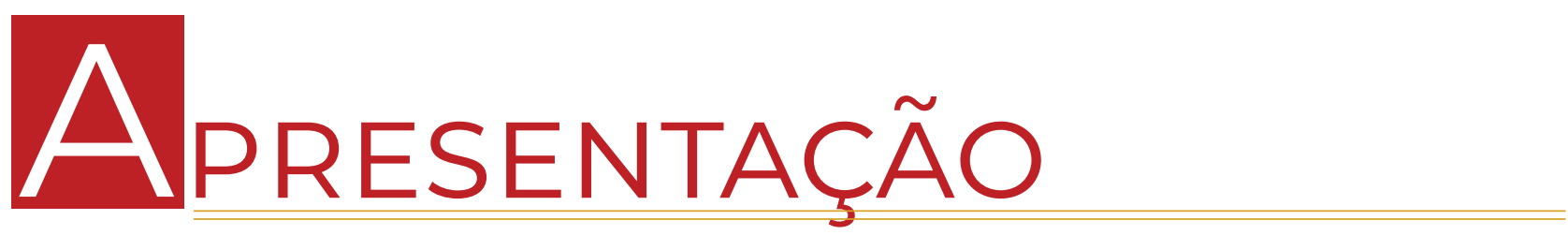

\title{
A URgENTE TAREFA DE RETOMARMOS O FUTURo POR MEIO DA TECNOCIÊNCIA
}

Dr. Rafael de Brito Dias

Orcid id: https://orcid.org/0000-0002-9702-2323

Faculdade de Ciências Aplicadas (FCA)

Universidade Estadual de Campinas (UNICAMP)

Dra. Milena Pavan Serafim

Orcid id: https://orcid.org/0000-0002-7541-4182

Faculdade de Ciências Aplicadas (FCA)

Universidade Estadual de Campinas (UNICAMP)

Msc. Matheus Henrique de Souza Santos

Orcid id: https://orcid.org/0000-0003-2873-4658

Universidade Estadual de Campinas (UNICAMP)

"O presente é melhor do que foi o passado". "O futuro será melhor do que o presente". Até há pouco, essas afirmações pareciam seguras, e eram reproduzidas com certa frequência por muitos de nós. Sobretudo para aquelas pessoas mais integralmente inseridas na dinâmica de trabalho-consumo das sociedades de capitalismo avançado, as possibilidades de realização material sem precedentes na história sustentaram por décadas a percepção de que o arranjo socioeconômico estabelecido garantiria a gradual melhoria das condições de vida da população, em direção a um futuro cada vez mais promissor.

A fé liberal no progresso, um dos pilares do pensamento Ocidental moderno, imputa à tecnociência o papel de motor das transformações socioeconômicas, como uma espécie de instrumento poderoso por meio do qual seria possível construir um futuro cada vez melhor. Conectam-se a essa racionalidade os campos da educação, da produção e do trabalho, nos quais realizar-se-iam as promessas da tecnociência. Confiando cegamente nessa ideia, adotamos estratégias coletivas por meio das quais deslocamos para o futuro o enfrentamento das urgências do presente. Ao fazê-lo, qual futuro construímos?

O imaginário social é hoje intensamente povoado por uma visão positiva acerca da ciência e da tecnologia: estas são geralmente compreendidas como motores inexoráveis que impulsionariam a humanidade em direção a um progresso material e moral não apenas possível, mas desejável (Sarewitz, 1996). Há, por outro lado, aqueles que reconhecem ciência e tecnologia como grandes fontes de problemas ambientais, econômicos, políticos e sociais e que eventualmente advogam pela recuperação de tradições e valores que estariam sendo destruídos pelo avanço dessas forças (Cutcliffe, 2003). Essas percepções polarizadas remetem a uma ambiguidade aparente nas relações entre tecnociência e sociedade. Uma análise mais aprofundada, porém, tende a nos conduzir a uma compreensão mais adequada da complexidade que envolve essa relação, organizada a partir do conjunto de valores que orientam o avanço da tecnociência no mundo contemporâneo.

Entendemos como tecnociência a união indissociável entre ciência e tecnologia num arranjo ordenado sob o capital, produzida a partir de valores como eficiência, produtividade, velocidade. Esses valores são instrumentalizados pelo capital por meio de mecanismos de controle cada vez mais sofisticados, aplicados às relações produtivas e de consumo, claro, mas que transcendem essas esferas e se fazem notar nas distintas dimensões da vida.

Interagimos cotidianamente com os artefatos, com as infraestruturas e com os sistemas à nossa volta. As megacidades, os complexos sistemas de transporte e as imbricadas cadeias de produção-circulação-consumo de bens e serviços são apenas alguns exemplos de arranjos dos quais a tecnologia é elemento constitutivo fundamental. Entretanto, embora rodeados por esses elementos - e sendo componentes do que poderíamos chamar de sociedades tecnológicas no sentido dado por Ellul $(1964,1990)$ - raramente pensamos na presença de tais valores na constituição da dimensão tecnológica do nosso mundo. Não obstante, eles estão presentes nos arranjos que nos cercam, construindo o particular ordenamento sociotécnico no nosso entorno.

A ampliação da compreensão sobre a natureza, os significativos avanços médicos e farmacêuticos, a incrível diversificação de bens e serviços disponíveis à escolha do consumidor são alguns dos resultados desse arranjo socioeconômico 
no qual estamos imersos. Ainda que essas transformações não tenham beneficiado a todos (significativa parcela da população mundial esteve, de fato, manifestamente apartada dos resultados desses processos), serviram como testemunho do poder transformador da tecnociência no mundo contemporâneo.

Ao longo das últimas décadas, contudo, tornaram se cada vez mais evidentes os custos das decisões tomadas no contexto da modernidade. O mesmo padrão de desenvolvimento tecnocientífico que nos trouxe esses espetaculares resultados ampliou também a instabilidade e a imprevisibilidade. Operou no sentido de desestruturar relações sociais e políticas consolidadas. Aprofundou desigualdades, acelerou a degradação ambiental e a destruição de ecossistemas, intensificou a emergência de novas doenças e seu ritmo de propagação em escala planetária.

Embora esse seja tema já enfrentado há tempo considerável no âmbito acadêmico - como por autores como Beck (2011) e Giddens (1991) - as urgências que hoje se apresentam não têm sido enfrentadas de modo a se construir uma efetiva estratégia de transição em direção a outro estilo de desenvolvimento. Essa percepção aponta para a questão fundamental que nos interessa aqui, que é a necessidade premente de imaginar o futuro que desejamos para, a partir disso, reprojetar o padrão tecnocientífico de modo a materializar essa visão. Evidentemente, não se trata de algo trivial.

Da forma como está organizado o atual padrão tecnocientífico, as decisões técnicas - de forma alguma neutras ou desprovidas de componentes políticos - são em larga medida monopolizadas por uma elite composta por políticos, burocratas, cientistas e engenheiros. Aos membros desse restrito grupo Feenberg $(2002,2010)$ denominou "senhores dos grandes sistemas técnicos". São eles os responsáveis pela tomada das decisões que reproduzem os valores (eficiência, velocidade, controle) a partir dos quais a tecnociência se desenvolve. No limite, isso significa que tem cabido a essa elite o papel de ditar os rumos do desenvolvimento socioeconômico.

Ampliar a participação da sociedade, até agora alheia à efetiva tomada de decisão na definição das configurações do sistema tecnocientífico, é fundamental. Pressupõe reconfigurar alianças e acordos. Mas envolve, como ponto de partida, reconhecer a concepção e a construção do futuro como tarefas que deveriam caber a todos nós.

Quando o progresso tecnocientífico é compreendido como panaceia, como solução automática para toda sorte de problemas e urgências, pode gerar um falso - e perigoso - sentimento de segurança. As contingências do presente tenderiam a ser percalços que, com o tempo, seriam eventualmente solucionadas pelos frutos do avanço da tecnociência. Essa percepção se revela, por exemplo, no conteúdo das críticas que têm sido recorrentemente direcionadas às Ciências Humanas, pautados na (equivocada) concepção de que não seriam "úteis" e, portanto, necessárias. A exaltação da utilidade, nesse caso, advém da percepção de que o conhecimento só é válido quando é claramente aplicado para geração de valor econômico. Essa ideia está vinculada ao conceito de inovação (tecnológica, principalmente).

A inovação- frequentemente compreendida como condição não apenas necessária, mas também suficiente para alavancar o desenvolvimento socioeconômico - não tem realizado efetivamente o papel que a narrativa moderna do progresso lhe reservava. Longe disso, como nos adverte Langdon Winner (2017), a fábula da inovação tem ocultado perversidades como a destruição de instituições e infraestruturas que costumavam garantir direitos fundamentais e promover acesso a serviços básicos. A inovação se tornou, nas palavras de Winner, "a joia da coroa do neoliberalismo".

Narrativas poderosas hoje amplamente difundidas levam, justamente, à constituição de conflitos latentes. O fetiche do empreendedorismo enquanto motor do capitalismo contemporâneo, o qual Barbrook \& Cameron (1996) associaram à "ideologia californiana"; a convicção de que a tecnociência atua como o motor inexorável que realizará as promessas do progresso (Sarewitz, 1996); o imaginário social centrado na visão do homem como tecnologicamente mais capaz que a mulher (Cockburn, 1985). Estes são alguns exemplos de algumas das narrativas que produziram a naturalização de conflitos no âmbito da tecnologia. Em alguns casos, uma mudança de consciência tem gerado a contestação de que o ordenamento sociotécnico estabelecido é um resultado natural da evolução das coisas. Em outros, os conflitos ainda permanecem latentes.

Para Sadowski e Manson (2014) a "ideologia californiana" representa a promessa de que as novas tecnologias permitiriam a criação de uma classe emergente de empreendedores capazes de realizar o potencial criativo das sociedades modernas por meio da livre iniciativa e da ação individual, sem qualquer tipo de vínculo com o Estado. Essa ideologia claramente se alinha aos princípios da Teoria liberal, que compreendem que apenas o mercado e a moral são elementos que surgem de forma espontânea (em contraposição a uma ordem social "criada" pelo Estado) e, portanto, possuem a verdadeira natureza da justiça e do avanço das sociedades modernas.

Esse pensamento, como mostrou Mazzucato (2011), não reflete a trajetória de desenvolvimento tecnológico e industrial das sociedades modernas, na qual a atuação estatal (conectada ao efetivo engajamento do setor privado) é constante e fundamental para promover os avanços tecnocientíficos. Contudo, vale mencionar que a apropriação privada dos frutos desse "progresso" tem, sim, ocorrido de maneira sistemática, porém geralmente questionada.

Essas reflexões nos conduzem a uma constatação importante: a de que a confiança exagerada na capacidade da tecnociência em gerar dinâmicas que propulsionem o desenvolvimento socioeconômico parece gerar um deslocamento focal importante. Confundimos avanço tecnocientífico com elevação de nossa condição; confiamos na tecnociência para solucionar toda sorte de problema, atual ou futuro. Com isso, perdemos de perspectiva a necessidade da ação imediata 
no presente: ora, se podemos contar com o poder da inovação tecnológica para erradicar a fome, garantir a oferta de serviços de qualidade para todos, atacar os imensos desafios sanitários e ambientais que hoje se apresentam, há o risco de esvaziamento da vida política. Ao confiar cegamente na tecnociência, esquivamo-nos da responsabilidade de nos organizarmos politicamente para, inclusive, definirmos o projeto a partir do qual será estabelecido o modelo de tecnociência do qual necessitamos.

É preciso, assim, gerar um novo deslocamento dessa perspectiva, de modo que nosso foco de atuação mire claramente a construção de um futuro possível por meio de ações claras e conscientes no presente. Para tanto, educação, produção, trabalho e política pública constituem esferas privilegiadas de reflexão e de organização. Os temas tratados neste número da Revista Espaço de Diálogo e de Desconexão - REDD conectam-se com esses espaços e trazem importantes apontamentos para (re)pensarmos a tecnociência e nosso futuro.

\section{REFERÊNCIAS}

BARBROOK, R. \& CAMERON, A. (1996) The Californian Ideology. Science as Culture, vol. 6, nº 1.

BECK, U. (2011) Sociedade de risco. Rumo a uma outra modernidade. São Paulo: Editora 34.

CUTCLIFFE, S. (2003) Ideas, máquinas y valores - los Estudios de Ciencia, Tecnología y Sociedad. México, D.F.: Anthropos Editorial.

ELLUL, J. (1964) The Technological Society. Nova York: Vintage Books.

ELLUL, J. (1990) The Technological Bluff. Grand Rapids: Eerdmans.

FEENBERG, A. (2002) Transforming technology: A critical theory revisited. Oxford: Oxford University Press.

FEENBERG, A. (2010) Between Reason and Experience: essays in Technology and Modernity. Cambridge, EUA: The MIT Press.

GIDDENS, A. (1991) As Consequências da Modernidade. São Paulo: Editora da UNESP.

MAZZUCATO, M. (2011) O Estado empreendedor. São Paulo: Companhia das Letras.

SADOWSKI, J. \& MANSON, P. (2014) 3-D print your way to freedom and prosperity: The hidden politics of the 'maker' movement'. Available at http://america.aljazeera.com/opinions/2014/5/3d-printing-politics.html.

SAREWITZ, D. (1996) Frontiers of illusion: science, technology and the politics of progress. Filadélfia: Temple University Press.

WINNER, L. (2017) “The Cult of Innovation: Its Colorful Myths and Rituals”. Disponível em https://www.langdonwinner.com/other-writings/2017/6/12/the-cult-of-innovation-its-colorful-myths-and-rituals. 